A DEMOCRATIZAÇÃO DO ACESSO AO ENSINO SUPERIOR:

\title{
CONSIDERAÇÕES SOBRE A ADESÃO DA UERN AO EXAME NACIONAL DO ENSINO MÉDIO ${ }^{1}$
}

\author{
SANTOS, Jean Mac Cole Tavares ${ }^{1^{*}}$; SILVA, Maria Kélia da $^{2^{* *}}$; MELO, Silvano Ferreira ${ }^{2^{* * *}}$ \\ ${ }^{1}$ Universidade do Estado do Rio Grande do Norte \\ ${ }^{2}$ Universidade Federal Rural do Semi-Árido \\ maccolle@hotmail.com* \\ marykellya@hotmail.com** \\ silvanoius@hotmail.com***
}

\section{RESUMO}

Analisa-se o processo de adesão ao Exame Nacional do Ensino Médio/Sistema de Seleção Unificada pela Universidade do Estado do Rio Grande do Norte, efetivado em 2015, objetivando perceber os processos de democratização do acesso à educação superior na referida universidade. Perscrutaram-se os ganhos que a adesão ao Exame Nacional pela universidade representa

para o acesso ao ensino superior na instituição. Os dados aqui organizados advieram de pesquisa bibliográfica. Ademais, os dados sobre o Exame Nacional, o Sistema Único de Seleção e o processo de adesão implantado pela universidade, dentre outros, foram obtidos de pesquisas a notícias e reportagens veiculadas principalmente em portais eletrônicos do governo e da instituição.

PALAVRAS-CHAVE: Enem. Sisu. Democratização. Ensino superior.

\section{THE DEMOCRATIZATION OF ACCESS TO HIGHER EDUCATION: CONSIDERATIONS ON THE}

\section{ADHERENCE OF UERN TO THE NATIONAL EXAMINATION OF MIDDLE SCHOOL}

\section{ABSTRACT}

The process of adherence to the National High School Examination/Unified Selection System by the State University of Rio Grande do Norte, carried out in 2015, aims to understand the processes of democratization of access to higher education in the university. The gains that the adhesion to the National Examination by the university represent for the access to higher education in

the institution were examined. The data here organized came from bibliographical research. In addition, the data on the National Exam, the Unified Selection System and the adhesion process implemented by the university, among others, were obtained from searches for news and reports mainly carried out in electronic portals of the government and the institution.

\section{LA DEMOCRATIZACIÓN DEL ACCESO A LA ENSEÑANZA SUPERIOR: CONSIDERACIONES SOBRE LA}

\section{ADHESIÓN DE LA UERN AL EXAMEN NACIONAL DE LA ENSEÑANZA MEDIA}

\section{RESUMEN}

Se analiza el proceso de adhesión al Examen Nacional de la Enseñanza Media/Sistema de Selección Unificada por la Universidad del Estado de Rio Grande do Norte, que se realizó en 2015, con el objetivo de percibir los procesos de democratización del acceso a la educación superior en la referida universidad. Se han explorado las ganancias que la adhesión al Examen Nacional por la universidad representa para el acceso a la enseñanza superior en la institución. Los datos aquí organizados son resultado de investigación bibliográfica. Además, los datos sobre el Examen Nacional, el Sistema Único de Selección y el proceso de adhesión implantado por la universidad, entre otros, fueron obtenidos de investigaciones a noticias y reportajes vehiculados principalmente en portales electrónicos del gobierno y de la institución.

PALABRAS CLAVE: Enem. Sisu. Democratización. Enseñanza superior.

1 Uma versão parcial e inicial do estudo foi publicada na Revista Holos (SANTOS; SILVA; MELO, 2017).

Educação \& Formação, Fortaleza, v. 2, n. 6, p. 165-185, set./dez. 2017

DOI: http://dx.doi.org/10.25053/edufor.v2i6.2580

http://seer.uece.br/redufor 


\section{INTRODUÇÃO}

A vigente Lei de Diretrizes e Bases da Educação (LDBEN) - Lei no 9.394, de 20 de dezembro de 1996 - dispõe, em seu artigo 51, acerca da autonomia das instituições de educação superior para deliberar sobre critérios e normas de seleção e admissão de seus alunos. 0 processo seletivo deve seguir todos os ditames da transparência, razão pela qual, nos termos do parágrafo 10 do artigo 44 da LDBEN, seu resultado precisa ser tornado público pelas instituições de ensino superior, sendo obrigatória a divulgação da relação nominal dos classificados, a respectiva ordem de classificação, bem como do cronograma das chamadas para matrícula, de acordo com os critérios para preenchimento das vagas constantes do respectivo edital.

As Instituições de Ensino Superior (IES), ao definirem os critérios a serem observados na seleção e admissão de estudantes, devem levar em conta os efeitos desses critérios sobre a orientação do ensino médio (artigo 51 da LDBEN). Contudo, com base no permissivo legal supracitado, pelo qual as instituições de educação superior tinham autonomia para deliberar sobre critérios e normas de seleção e admissão de seus alunos, o fim da obrigatoriedade do vestibular levou à multiplicidade de novas formas de seleção de candidatos às vagas nas universidades, que, na prática, pela pluralidade admitida, não garantiam, necessariamente, a democratização do processo de seleção de discentes.

A porta de entrada para a educação superior, nos termos da LDBEN, estava sendo, pois, utilizada para admitir aceitação de cartas de recomendação de empresas, reservas de vagas para alunos de colégios conveniados, "vestibulinhos" pré-agendados, entre outras inovações, que nem sempre garantiam os princípios da legalidade, moralidade, igualdade, transparência, dentre outros. Todo esse contexto de irregularidade na forma de seleção e admissão de estudantes no ensino superior fez com que o Exame Nacional do Ensino Médio (Enem), em 1998, aparecesse como a oportunidade de moralizar o processo de seleção de aluno.

O Enem, logo nos primeiros anos posteriores à sua instituição, passaria a constituir uma das principais alternativas ao vestibular, sobretudo porque se tratava de uma inovação que bem se alinhava às novas diretrizes curriculares do ensino médio e às orientações da Constituição Federal e da LDBEN. Logo após a sua instituição, foram crescentes as adesões ao Enem por parte

Educação \& Formação, Fortaleza, v. 2, n. 6, p. 165-185, set./dez. 2017

DOI: http://dx.doi.org/10.25053/edufor.v2i6.2580

http://seer.uece.br/redufor 
das instituições de ensino superior, e isso o consolidava, dia após dia, edição após edição, atingindo a dimensão atual, como veremos mais adiante.

Acompanhando o aumento do Enem e também buscando impulsioná-lo, o governo foi desenvolvendo diversos programas de acesso ao ensino superior, cuja sistemática utiliza a nota obtida no exame. Assim, atualmente, com a nota do exame, o candidato pode concorrer, por meio do programa Universidade para Todos (ProUni), às vagas oferecidas por meio de bolsas de estudo integrais ou parciais em instituições particulares de educação superior; ou concorrer, com a mesma nota obtida no exame, por meio do Sistema de Seleção Unificada (Sisu), às vagas oferecidas em instituições públicas de ensino superior. O resultado do exame também é utilizado como requisito de seleção para receber o benefício do Fundo de Financiamento Estudantil (Fies), dentre outros programas.

Essa realidade, que se espalhou por todo o país, chegou à Universidade do Estado do Rio Grande do Norte (UERN). O processo de seleção para o acesso aos cursos de graduação da UERN passou, com a instituição do Enem, a utilizar, facultativamente, a nota conjugada do Processo de Seleção Vocacionado (PSV) e do Enem; em seguida, com a adesão ao Sisu, em 2015, parte das vagas foram preenchidas pelo PSV; e a outra parte, pelo Sisu; e, finalmente, a partir de 2016, todas as vagas dos cursos de graduação da UERN passaram a ser preenchidas apenas por meio do Sisu, com base na nota do Enem.

Segundo matérias dos jornais locais ${ }^{2}$, durante o democrático processo de discussão com a comunidade, os dirigentes da universidade deixaram claro que a adesão ao exame estaria ligada diretamente à questão financeira, apesar de o foco ser na possibilidade de propiciar processos mais democráticos de acesso ao ensino superior. Portanto, a UERN aderiu ao Enem/Sisu anunciando o processo democrático de construção da adesão, ouvindo toda a comunidade, e a possibilidade de democratização do acesso aos seus cursos, já que propiciaria condições mais justas e iguais entre os concorrentes.

Diante disso, este artigo analisa o processo de adesão da UERN ao Enem e ao Sisu para seleção de candidatos aos seus cursos de graduação, objetivando perceber a democratização do acesso à educação superior, tida como referendada na expansão de vagas, na facilitação da inscrição, na possibilidade de universalização e de condições mais justas e iguais no acesso aos

2 Ver os jornais De fato de 22 de maio de 2014 e O mossoroense de 21 de maio de 2014.

Educação \& Formação, Fortaleza, v. 2, n. 6, p. 165-185, set./dez. 2017

DOI: http://dx.doi.org/10.25053/edufor.v2i6.2580

http://seer.uece.br/redufor 
cursos de graduação oferecidos pela UERN. Como referência para este estudo, pensamos democracia/democratização com as concepções de Martin Trow, como apresentado por Ristoff (2014). Os dados sobre o Enem, o Sisu e o processo de adesão da UERN foram obtidos de pesquisas a notícias e reportagens veiculadas no portal do Instituto Nacional de Estudos e Pesquisas Educacionais Anísio Teixeira (Inep), do Sisu, do Enem e da UERN, principalmente.

\section{ENEM: CONTEXTUALIZAÇÃO, INSTITUIÇÃO E CONSOLIDAÇÃO}

A Constituição Federal (CF) de 1988 eleva a educação à condição de direito fundamental, indispensável à manutenção da dignidade humana de todo indivíduo. Assim como a saúde, a alimentação, a moradia, a segurança e outros, a educação é um direito social fundamental (artigo 6으, caput, da CF), sem a qual nem as pessoas nem o próprio Estado poderão trilhar perspectiva de crescimento e desenvolvimento, objetivo fundamental da República Federativa Brasileira, nos termos do artigo $3 \circ$, inciso II, da CF.

Somente a educação é capaz de incutir nos indivíduos, de forma geral, o senso de justiça social e solidariedade, a ideia de que todos são iguais e merecedores dos mesmos direitos, bem como de suscitar o ânimo necessário para a busca do crescimento pessoal e profissional. Com a educação, busca-se o "[...] pleno desenvolvimento da pessoa, seu preparo para o exercício da cidadania e sua qualificação para o trabalho" (CF, artigo 205, parte final), por meio da erradicação do analfabetismo, universalização do atendimento escolar, melhoria da qualidade do ensino, formação para o trabalho, promoção humanística, científica e tecnológica do país e estabelecimento de meta de aplicação de recursos públicos em educação (CF, artigo 214, incisos I a VI).

Todos têm direito à educação, a qual será promovida e incentivada, de forma permanente, pelo Estado, pela família e por toda a sociedade (CF, artigo 205). O dever do Estado de promover a educação se estende da educação infantil aos níveis mais elevados do ensino. Ao Estado compete promover o acesso aos níveis mais elevados do ensino, da pesquisa e da criação artística, segundo a capacidade de cada um (CF, artigo 208, inciso V). Os sistemas de ensino da União, dos estados, do Distrito Federal e dos municípios são organizados de forma colaborativa, de modo a assegurar a universalização do ensino obrigatório (CF, artigo 211, caput e parágrafo 
4ํ). Assim, é competência da União, dos estados e do Distrito Federal legislar sobre educação e ensino, mas é reservado, privativamente, à União legislar sobre as Diretrizes e Bases da Educação Nacional com o intuito de instituir o Plano Nacional de Educação (PNE).

Com base no comando constitucional, é instituída a Lei no 9.394, de 20 de dezembro de 1996, que estabelece as Diretrizes e Bases da Educação Nacional. A educação escolar, nos termos do artigo 21, incisos I e II, da LDBEN, compõe-se de dois níveis: a educação básica e a educação superior. A educação básica é formada pela educação infantil, ensino fundamental e ensino médio. "A educação básica tem por finalidades desenvolver o educando, assegurar-lhe a formação comum indispensável para o exercício da cidadania e fornecer-lhe meios para progredir no trabalho e em estudos posteriores" (LDBEN, artigo 22). A educação superior abrange diversos cursos e programas, como graduação, mestrado e doutorado, cursos sequenciais e de extensão (LDBEN, artigo 44, incisos I a IV). A porta de entrada para a educação superior é a graduação, aberta a candidatos que tenham concluído o ensino médio ou programa de estudo equivalente e tenham sido classificados em processo seletivo (LDBEN, artigo 44, inciso II).

Antes mesmo da instituição do Enem, a vigente LDBEN já acabara com a obrigatoriedade do vestibular, ao dispor, em seu artigo 51, sobre a autonomia das instituições de educação superior para deliberar sobre critérios e normas de seleção e admissão de seus alunos. Com base nesse permissivo legal, o fim da obrigatoriedade do vestibular levou à multiplicidade de novas formas de seleção de discentes - não muito plurais, tampouco éticas: houve instituições particulares de ensino superior que passaram a aceitar cartas de recomendação de empresas no ingresso de estudantes; outras definiram como critério de seleção e admissão o histórico escolar do ensino médio; houve ainda instituições que chegaram a reservar vagas para educandos de colégios conveniados. Esse contexto fez com que o Enem se transformasse, nos anos seguintes à sua instituição, numa das principais alternativas ao vestibular, sobretudo porque se tratava de uma inovação que bem se alinhava às novas diretrizes curriculares do ensino médio e às orientações da LDBEN.

O Enem foi instituído em 1998, por meio da Portaria no 438, de 28 de maio, do Ministério de Estado da Educação e do Desporto. No mesmo ano em que foi instituído, o Enem experimentou sua primeira edição, sendo muito bem avaliado por diversas instituições de ensino superior, que logo demonstraram a possibilidade e o interesse em adotá-lo como alternativa ao vestibular, ou 
pelo menos como parte da nota necessária para ingresso de alunos ao ensino superior, embora a utilização do Enem não fosse obrigatória. Assim, logo nos anos seguintes à primeira edição, diversas instituições de ensino superior passaram a adotar a nota do Enem como meio de ingresso, e o número de instituições que aderiram a essa nova alternativa foi crescente dia após dia.

Em sua página na internet ${ }^{3}$, em matéria do dia 18 de junho 1999, o Inep divulgou uma lista com os nomes de 25 universidades que haviam confirmado o uso dos resultados do Enem como um dos critérios de acesso ao ensino superior. Na lista, constavam nomes como: Universidade de São Paulo (USP/SP), Universidade Estadual de Campinas (Unicamp/SP), Universidade Estadual Paulista (Unesp/SP), Universidade Federal de São Paulo (Unifesp/SP), Universidade Federal de Ouro Preto (Ufop/MG), Universidade Federal de Lavras (UFLA/MG), Universidade da Amazônia (Unama/PA), Universidade Federal de Pelotas (UFPEL/RS), Pontifícia Universidade Católica de Campinas (PUC/Campinas/SP), Pontifícia Universidade Católica do Rio de Janeiro (PUC/Rio/RJ), Universidade Federal do Paraná (UFPR/PR), dentre muitas outras.

Nesse processo de adesão, a PUC/Rio saiu na frente, destinando $20 \%$ das vagas abertas em 1999 para candidatos que alcançaram mais de 70\% de aproveitamento no exame. A Universidade do Grande $A B C$ (UniABC), de São Caetano do Sul (SP), foi mais ousada, ao comunicar ao Inep sobre a substituição do vestibular do ano 2000 pelos resultados do Enem de 1999, tornando-se, assim, a primeira instituição de ensino superior do país a decretar o fim do vestibular. Os critérios referentes à utilização da nota do Enem na seleção de ingresso variavam de instituição para instituição.

Já em 8 de novembro de 1999, o Inep divulgou uma nova lista de adesões ao Enem: a lista de 25 adesões do dia 18 de junho cresceu para 87, das quais 12 eram de instituições públicas e 75 de instituições privadas. Em 14 de dezembro de 1999, o número já chegava a 93 adesões. Em 29 de agosto de 2002, em todo país o número de adesões já havia ampliado consideravelmente: 338 instituições de ensino superior comunicaram ao Inep acerca da utilização do Enem em seus vestibulares, sendo 44 públicas e 294 privadas. Dois anos depois, em 14 de maio de 2004, o Enem já estava presente nos vestibulares de $21 \%$ das instituições de ensino superior do Brasil. Dos 2.084 estabelecimentos de ensino superior existentes no país à época,

3 Disponível em: <http://portal.inep.gov.br/todas-noticias>. Acesso em: 22 jun. 2016.

Educação \& Formação, Fortaleza, v. 2, n. 6, p. 165-185, set./dez. 2017

DOI: http://dx.doi.org/10.25053/edufor.v2i6.2580

http://seer.uece.br/redufor 
436 haviam demonstrado o interesse na utilização dos resultados da avaliação como critério de seleção: 54 instituições públicas e 382 particulares.

Rapidamente o Enem se consolidava como uma nova forma de seleção de alunos ao ensino superior. $E$ as crescentes e rápidas adesões ao Enem por instituições de ensino superior em todo o país, logo após a sua primeira edição, em 1998, foram determinantes para incentivar a participação dos estudantes no exame. Desde a primeira edição, ano após ano, o número de inscritos e de participantes no Enem foi cada vez maior. E esse grande sucesso experimentado pelo exame ao longo de todos esses anos se deve, em primeiro lugar, às adesões ao resultado do Enem em complementação ou em substituição ao vestibular propostas por diversas instituições de ensino superior de todo o país.

Segundo o portal do Inep, em matéria divulgada em 16 de dezembro de 1998, a primeira edição do Enem, aplicada em 30 de agosto do mesmo ano, em 184 municípios, incluindo todas as capitais, contou com a participação de 115.575 alunos concluintes e egressos do ensino médio, de um total de 157.221 inscritos. Na segunda edição do exame, realizado em 29 de agosto de 1999, em 162 municípios, incluídas todas as capitais, e em 282 locais de provas, conforme matéria publicada em 14 de dezembro do mesmo ano, o número de participantes, em comparação com a primeira edição, mais que dobrou, saltando para 315.960 alunos, de um total de 346.953 inscritos. A abstenção (9\%), por sua vez, foi bem abaixo da registrada no primeiro exame $(26,5 \%)$.

A oitava edição (Enem 2005), aplicada em 4.375 locais de prova, distribuídos em 730 municípios das 27 unidades da federação, conforme matéria publicada em 30 de dezembro de 2005, contou com a participação de cerca de 2,2 milhões de candidatos, número que corresponde a $74,79 \%$ dos 3.004 .491 inscritos. O crescimento considerável do número de inscritos no Enem de 2005 em relação às edições anteriores do exame deveu-se ao ProUni, do Ministério da Educação (MEC), que utiliza os resultados do Enem como um dos critérios para selecionar os contemplados com bolsas de estudo integrais ou parciais em instituições privadas de ensino superior.

A edição de 2010 do Enem apresentou um salto ainda maior: conforme matéria de 5 de novembro de 2010, mais de 4,6 milhões de pessoas se inscreveram para fazer o exame, que foi aplicado em cerca de 16.000 localidades, distribuídas em cerca de 1.800 municípios de todos os estados brasileiros. Além da oportunidade de utilização do resultado do Enem de 2010 para 
concorrer às bolsas do ProUni, havia agora também a oportunidade de utilizar o mesmo resultado do exame para concorrer às vagas oferecidas pelo Sisu.

Em 2015, o leque de possibilidades de estudo a partir do resultado do Enem se ampliou, graças aos implementos de novas políticas públicas de educação, e isso fez com que o número de inscrições no exame fosse ainda maior: conforme matéria divulgada em 20 de outubro de 2015, mais de 7,7 milhões de pessoas se inscreveram para fazer o exame, dos quais $78 \%$ efetivamente realizaram a prova.

Atualmente, com a nota do exame, o candidato pode concorrer, mediante o programa ProUni, às vagas oferecidas por meio de bolsas de estudo integrais ou parciais em instituições particulares de educação superior; ou concorrer, com a mesma nota obtida no exame, por meio do Sisu, às vagas oferecidas em instituições públicas de ensino superior. O resultado do exame também é utilizado como requisito de seleção para receber o benefício do Fies, dentre outros programas.

As adesões ao Enem inegavelmente tornaram o acesso ao ensino superior mais cômodo e democrático, ao permitir que o mesmo resultado do exame seja utilizado para concorrer às vagas oferecidas por diversas instituições de ensino em qualquer local do país. Tudo isso revela a importância do Enem como instrumento de seleção para a distribuição das políticas públicas de educação.

\section{A UERN E A ADESÃO AO ENEM: DO PSV AO SISU}

Desde sua instituição, em 1998, até o momento presente, centenas de instituições passaram a aderir ao Enem, inicialmente como complementação ao vestibular, depois em sua substituição. Com a UERN não se deu diferente: primeiro a universidade, de forma modesta, passou a aproveitar a nota do exame, de forma facultativa, em complementação à do Processo de Seleção Vocacionado (PSV), até passar a substituir totalmente, a partir de 2016, o PSV pelos resultados do Enem.

Antes do PSV, a UERN adotava o vestibular. Em verdade, o vestibular era uma realidade da época em que a universidade se chamava Universidade Regional do Rio Grande do Norte (URRN). Com a mudança da denominação, em 1999, para Universidade do Estado do Rio Grande 
do Norte (UERN), o vestibular foi substituído pelo PSV em 2000. No vestibular, os candidatos participam de provas que abordam todas as disciplinas; por outro lado, no PSV, as provas são constituídas de grupos de disciplinas afins aos cursos ofertados.

Posteriormente, a UERN passou a adotar um sistema no qual a classificação de candidatos para o acesso aos cursos de graduação da UERN - para preenchimento de vagas iniciais autorizadas pelo Conselho de Ensino, Pesquisa e Extensão (Consepe) - faz-se a) ou por meio do PSV de forma isolada, b) ou por meio do PSV combinado com o Enem (UERN, 2014).

A escolha da modalidade isolada ou combinada é feita pelo candidato no ato de inscrição. Assim, ao efetivar sua solicitação de inscrição, o candidato fará opção por uma das seguintes modalidades: ou pelo PSV de forma isolada, equivalente a $100 \%$ do total de pontos; ou pelo PSV, equivalente a $80 \%$, combinado com o Enem, equivalente a $20 \%$ do total de pontos (UERN, 2014).

O sistema acima descrito teve sua última aplicação no processo de seleção para preenchimento das vagas iniciais dos cursos de graduação da UERN no ano letivo de 2014. Essa sistemática foi substituída por uma nova, em que não é mais obrigatória a realização do PSV para concorrer às vagas ofertadas, como foi exigido até o Edital no 13/2013 para o PSV 2014. Assim, no processo de preenchimento das vagas iniciais dos cursos de graduação da UERN no ano letivo de 2015, o candidato não mais pôde combinar a nota do Enem com a do PSV: ou utilizava só a do PSV, ou somente a do Enem. Nessa nova sistemática, decorrente da adesão da UERN ao Sisu, materializada pelo Edital no 13/2014 (Comperve), para o Processo Seletivo de Vagas Iniciais (PSVI), 40\% das vagas iniciais para o ano letivo de 2015 foram preenchidas por meio do PSV, e 60\% por meio do sistema Enem/Sisu (UERN, 2015). Quanto ao PSV, para preenchimento de $40 \%$ das vagas iniciais para o ano letivo de 2015 , segue as mesmas regras que expusemos acima, iguais às constantes do Edital no 15/2003 (Comperve).

A adesão da UERN ao Sisu foi realizada em 5 de dezembro de 2014, por ato do magnífico reitor, o Sr. Pedro Fernandes Ribeiro Neto. Tal adesão, que representa o objetivo da universidade em utilizar a nota do Enem, via plataforma do Sisu, para o preenchimento de suas vagas de graduação a partir do ano letivo de 2015, foi formalizada pela assinatura do Termo de Adesão (1 edição de 2015) da Secretaria de Educação Superior (Sesu) do MEC.

Educação \& Formação, Fortaleza, v. 2, n. 6, p. 165-185, set./dez. 2017 
A adesão da UERN ao Sisu não foi integral, haja vista que 25 cursos da UERN não participaram do Sisu em 2015, representando um total de 865 vagas que foram preenchidas pelo velho sistema do PSV. A destinação de $60 \%$ das vagas para seleção mediante o sistema Enem/Sisu representa uma transição para a oferta de $100 \%$ das vagas apenas pelo sistema Enem/Sisu. A adesão integral da UERN ao Sisu, que provavelmente ocorrerá em breve, representará o fim da utilização do PSV para o preenchimento das vagas de graduação da universidade.

\section{O PRINCÍPIO DEMOCRÁTICO, A DESIGUALDADE EDUCACIONAL E O ELITISMO DO SISTEMA DE ACESSO AO ENSINO SUPERIOR NO BRASIL}

O Brasil é uma República Federativa, constituída em Estado Democrático de Direito (CF,

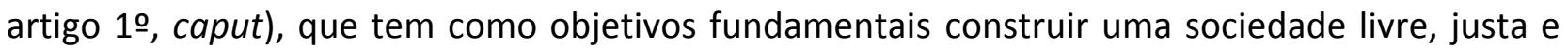
solidária, promovendo o bem de todos, sem preconceitos de origem, raça, sexo, cor, idade e quaisquer outras formas de discriminação, de forma a erradicar a pobreza e a marginalização e reduzir as desigualdades sociais e regionais, com vista a garantir o desenvolvimento nacional (CF artigo 3으, incisos I a IV). Todos esses objetivos fundamentais constituem valores que devem orientar o Estado brasileiro em todas as suas ações e decorrem diretamente do princípio democrático.

O princípio democrático, que perpassa toda a Constituição Federal, nutre as ações públicas de valores como justiça, equidade e solidariedade. O Estado brasileiro apresenta grande desigualdade social e regional, e isso tem essencial explicação histórica e se deve, sobremaneira, à vasta dimensão territorial. Mais do que apenas e meramente econômica, as desigualdades social e regional refletem-se também e inevitavelmente no aspecto educacional: é profunda a desigualdade educacional entre brancos e negros, entre ricos e pobres, entre os que moram no campo e na cidade, entre os que moram no Norte e no Sul. Por questões de cor, de classe econômica e de localização geográfica, ainda é grande a desigualdade educacional no país. E é justamente por isso que o legislador constituinte de 1988 incutiu na Constituição Federal a necessidade de se promover o bem de todos, sem preconceitos de qualquer natureza, segundo os valores de justiça e solidariedade, pois sem isso não há formas de se combater a imensa desigualdade social e regional existente no Brasil - problema de cuja solução depende o desenvolvimento nacional. 
O problema educacional brasileiro não é, pois, episódico; decorre da própria construção histórica do país, marcada pela desigualdade social e regional. Por muito tempo, houve a centralização da educação nos grandes centros, restrita às classes sociais mais abastadas. Promover o desenvolvimento educacional, com vista a expandir seu acesso a todos, estava fora das prioridades dos governos que dirigiram o Brasil nesses mais de 500 anos. Educação sempre foi um direito de poucos, em outras palavras, sempre existiu no Brasil um sistema elitista de acesso ao ensino superior. O sistema de educação superior é elitista, pois apenas permite acesso a até 15\% dos jovens em idade apropriada (TROW apud RISTOFF, 2014).

Mas esse quadro histórico começa a mudar, sobretudo nas últimas duas décadas, momento em que se percebe uma nítida e continuada implementação de políticas públicas educacionais expansionistas e universais, voltadas, efetivamente, para melhorar a educação superior no país. Nesse período:

[...] a educação superior brasileira foi marcada por forte expansão sob todos os aspectos: cresceu o número de instituições, de cursos, de vagas, de ingressantes, de matrículas e de concluintes. Foi um crescimento constante e significativo, com marcada aceleração de ritmo de 1999 a 2003, durante o segundo mandato do governo Fernando Henrique Cardoso - período em que observamos altas taxas de crescimento da educação superior, notadamente em função da proliferação de instituições privadas, muitas delas, e.g., Centros Universitários e Universidades, dotados de autonomia para criar novos cursos e aumentar o número de vagas ofertadas. Nos doze anos dos governos Lula-Dilma, o crescimento se manteve constante, embora em ritmo mais moderado, e mais em sintonia com as políticas globais de inclusão social, passando a expansão a estar visceralmente associada à democratização do campus brasileiro e orientada por um conjunto de políticas estruturantes implantadas nos últimos anos. (RISTOFF, 2014, p. 724).

Todo esse crescimento se dá, portanto, em momento posterior à Constituição Federal de 1988. A própria Carta Cidadã foi redigida com um viés prospectivo quanto ao futuro da educação brasileira, o que reflete a preocupação do legislador constituinte com a situação calamitosa da educação no país. Isso, no entanto, revela que o Brasil já atingiu um sistema de educação superior de massas, deixando para trás o sistema elitista, que privilegiava alguns poucos indivíduos das classes mais favorecidas economicamente? Para responder a essa pergunta, entendamos primeiramente o que é o sistema elitista, o sistema de massa e o sistema universal, nos termos preconizados por Martin Trow.

Segundo a classificação proposta por Martin Trow, o sistema de educação superior em um determinado país pode encontrar-se em um destes três níveis de desenvolvimento: o sistema 
elitista, o sistema de massa e o sistema universal. Para Trow, um sistema de educação superior é considerado de elite, elitista, se nesse sistema de educação o acesso ao ensino superior abrange aproximadamente até $15 \%$ dos jovens de idade apropriada. Em outras palavras, se em um determinado país, da totalidade dos jovens em idade apropriada para ingressar na universidade, apenas $15 \%$ ou menos desses jovens têm acesso ao ensino superior, então vigora nessa nação um sistema elitista de acesso ao ensino superior. Se, por sua vez, o percentual de acesso desses jovens encontra-se entre $16 \%$ e $50 \%$, o sistema de educação superior é considerado de massa. Assim, o sistema de massas se consolida quando atinge $30 \%$ de acesso. Por fim, a partir de 50\%, o sistema de acesso ao ensino superior é considerado universal (TROW apud RISTOFF, 2014).

No Brasil, não obstante o salto que a educação superior tenha dado de 1990 à atualidade, ainda vige um sistema de acesso ao ensino superior basicamente elitista. Muito melhoramos em termos de expansão da educação superior nesse período de mais de 20 anos que sucedeu a Constituição Federal de 1988 e no qual se consolidou a democracia brasileira, mas ainda continua a vigorar no Brasil o elitismo do sistema de acesso ao ensino superior. Felizmente, podemos ser otimistas e acreditar que vivemos um período de transição, em que sairemos do tradicional modelo elitista para incorporar um sistema de massa. "O Brasil [...] começa apenas a querer sair de um sistema de acesso de elite [...], [pois,] para consolidar um sistema de massas, o Brasil precisa pelo menos atingir a meta de 33\% recentemente aprovada, no novo Plano Nacional de Educação (PNE), para o ano 2024" (RISTOFF, 2014, p. 726).

\section{A DEMOCRATIZAÇÃO DO ACESSO AO ENSINO SUPERIOR PROMOVIDA PELA UERN: UMA ANÁLISE À LUZ DA ADESÃO AO ENEM/SISU}

Consideramos democrático um sistema de massa ou universal de acesso ao ensino superior, nos termos que acima apresentamos, segundo a classificação proposta por Martin Trow. E mais do que isso, um sistema que promova uma isonomia efetiva de oportunidades de acesso a todos aqueles que desejam ingressar no ensino superior. Entendemos por efetiva isonomia aquela que se filia aos processos históricos de exclusão de determinadas classes sociais e busca compensá-las. Em outras palavras, um sistema verdadeiramente democrático de acesso ao ensino superior é aquele que vai além da mera igualdade formal, privilegiando a igualdade 
material, o que significa reconhecer a desigualdade existente entre os sujeitos de uma sociedade, a fim de dar tratamento especial aos menos favorecidos para que efetivamente possam usufruir em iguais condições com os mais favorecidos. Dar um tratamento verdadeiramente isonômico "[...] significa tratar igualmente os iguais e desigualmente os desiguais, na exata medida de suas desigualdades" (NERY JUNIOR, 1999, p. 42).

Nesse contexto, democratizar o acesso ao ensino superior é criar mecanismos que possibilitem e facilitem o ingresso no ensino superior, de forma a contemplar todos os indivíduos, independentemente de sexo, cor, condição econômica, localização geográfica, etc. Isso não pode ser diferente, porque o Brasil, sendo uma República Federativa, constituída em Estado Democrático de Direito (CF, artigo 1ㅇ, caput), tem valores democráticos que devem ser protegidos. Tanto é que o Brasil tem como objetivos fundamentais construir uma sociedade livre, justa e solidária, promovendo o bem de todos, sem preconceitos de origem, raça, sexo, cor, idade e quaisquer outras formas de discriminação, de forma a erradicar a pobreza e a marginalização e reduzir as desigualdades sociais e regionais, com vista a garantir o desenvolvimento nacional (CF, artigo 3으, incisos I a IV). Assim, no contexto da educação, promover mecanismos que possibilitem e facilitem o acesso de todos ao ensino superior constitui também, de forma reflexa, um objetivo fundamental a ser perseguido e fomentado pelo Estado brasileiro.

Os mecanismos seletivos da educação superior não podem se desvincular do contexto histórico-social da realidade nacional, marcado por forte preconceito e exclusão contra negros e pobres, que apresenta imensa desigualdade econômica e educacional, a qual sempre foi caracterizada pelo elitismo do sistema de acesso à universidade. É preciso ter-se em mente que o Brasil é um país de grandes contrastes, especialmente culturais e econômicos, que impactam fortemente a distribuição das oportunidades de mercado e de educação. Dessa forma, é imprescindível, para que conquistemos um sistema de massa e verdadeiramente democrático, que busquemos desenvolver mecanismos que possam propiciar aos negros e aos pobres conquistar vagas nas universidades. Felizmente, nas duas últimas décadas, após a promulgação da Carta Cidadã, tais mecanismos foram sendo paulatinamente criados, viabilizando um salto sem precedentes na história da educação superior no Brasil.

Educação \& Formação, Fortaleza, v. 2, n. 6, p. 165-185, set./dez. 2017

DOI: http://dx.doi.org/10.25053/edufor.v2i6.2580

http://seer.uece.br/redufor 
Da promulgação da Constituição Federal de 1988 para cá - orgulhemo-nos de enfatizar -, diversas instituições de ensino superior foram criadas, tanto federais quanto estaduais e municipais; tanto públicas quanto privadas; o número de vagas e de cursos cresceu múltiplas vezes mais; as universidades chegaram ao interior, em diversas regiões afastadas dos grandes centros; foram criados o Enem, o ProUni, o Fies, o Sisu e diversos outros programas de facilitação ao acesso ao ensino superior; cotas para negros, cotas para alunos de escolas públicas, cotas para deficientes, etc. Todos esses mecanismos foram criados com a nítida finalidade de fazer com que a classe menos favorecida da sociedade pudesse ocupar os bancos das universidades públicas e privadas do país, de forma a desvincular o acesso ao ensino superior da capacidade econômica. Educação é direito de todos, e esse direito só pode ser objetivamente usufruído se for possível alcançá-lo diretamente, sem tantas barreiras de ordem econômica, estrutural e geográfica. Não basta somente exaltar a existência de um direito, é preciso criar a ponte de acesso a ele - é o que tem sido feito nos últimos anos, felizmente. O Brasil trilha o caminho da democratização do acesso ao ensino superior, vivendo, nesse contexto, um momento de transição de um sistema elitista para um sistema de massa da educação superior.

Em contexto regional - voltando agora os olhos para o estado do Rio Grande do Norte -, as engrenagens também giram em consonância com essa mesma ideia de democratizar o acesso ao ensino superior, e isso se percebe em vários contextos: a própria decisão de implantar o Campus Central da UERN no município de Mossoró é uma decisão consonante com a democratização do acesso ao ensino superior, por permitir uma descentralização dos campi universitários da capital e da região metropolitana.

Com a implantação da UERN em Mossoró, a população do Oeste potiguar pôde ingressar no ensino superior sem ter que se deslocar para a capital - algo que constitui uma façanha hoje, quiçá outrora. As universidades concentradas nas capitais do país criavam, para as pessoas do interior, uma dificuldade geográfica e econômica de ingresso no ensino superior. Com a instituição da UERN em Mossoró, as pessoas do Oeste potiguar puderam ingressar na universidade com mais facilidade. A situação da educação superior do interior potiguar melhorou ainda mais com a criação de diversos campi da UERN em localidades estratégicas, como o Campus Avançado de Assu, o Campus Avançado de Pau dos Ferros, o Campus Avançado de Patu e o Campus do Seridó, em Caicó, sem falar da criação, em 2002, do Programa de Interiorização da 
UERN, com a instalação dos Núcleos de Educação Superior. A questão geográfica de centralização das universidades nas capitais, portanto, é um problema que dificulta o acesso ao ensino superior por parte daqueles que moram em munícipios afastados no interior; problema que, no exemplo potiguar, teve a UERN como primeiro e principal mecanismo saneador.

Mas a contribuição da UERN com a democratização do acesso ao ensino superior na região potiguar não se limita ao aspecto geográfico, com a instalação do Campus Central em Mossoró e a distribuição de campi nos munícipios de Assu, Pau dos Ferros, Patu e Caicó. A UERN também tem promovido a democratização do acesso ao ensino superior por meio de diversos mecanismos de natureza sociocultural e econômica, criando maior oportunidade de acesso aos seus cursos de graduação aos estudantes de famílias mais pobres e portadores de deficiência.

Assim, em cumprimento à Lei Estadual no 8.258, de 27 de dezembro de 2002, que trata da reserva social de vagas, a UERN oferta $50 \%$ das vagas iniciais distribuídas por campus, núcleos, cursos, habilitação, turno e semestre letivo aos alunos que tenham cursado integralmente o ensino fundamental e médio em escola pública (UERN, 2014, 2015). A reserva de metade das vagas para discentes oriundos de escolas públicas cumpre uma importante função social de democratização do acesso ao ensino superior, pois esses alunos, por não terem tido oportunidades de uma formação educacional básica de qualidade - é inquestionável que a educação pública no Brasil está muito aquém dos padrões de qualidade desejados e que são ofertados nas instituições de ensino privadas -, estão em grande desvantagem na disputa com os estudantes oriundos de escolas privadas por uma vaga na universidade.

A reserva social de vagas, dessa forma, constitui um ativismo jurídico importante de promoção de oportunidade de acesso ao ensino superior por parte daqueles que não têm condições de pagar por uma formação educacional inicial de qualidade. Reservar parte das vagas e permitir que estudantes de escolas públicas concorram entre si por uma vaga na universidade é uma importante medida de democratização do acesso ao ensino superior, por permitir uma igualdade material do direito de ir à universidade. Iguais considerações são estendidas à reserva de vagas para pessoas com deficiência, em atendimento à Lei Estadual no 9.696, de 25 de fevereiro de 2013, combinada com a disposição do artigo 5o do Decreto no 5.296, de 2 de dezembro de 2004, que destina 5\% das vagas iniciais - distribuídas por campus, curso, 
habilitação, turno e semestre letivo da UERN - a candidatos, exclusivamente, com deficiência comprovada por profissional cadastrado pelo Sistema Único de Saúde (SUS).

Feitas essas considerações iniciais, que demonstram a importante atuação da UERN na promoção da democratização do acesso ao ensino superior no Oeste potiguar, pergunta-se: e, quanto à adesão, em 2015, da UERN ao Sisu, haverá alguma contribuição no sentido de facilitar o acesso aos cursos de graduação da universidade, de forma a fomentar a democratização, em algum aspecto, do acesso ao ensino superior no Meio-Oeste potiguar? É uma reflexão feita em futuro do presente, porque ainda é um passo novo dado pela UERN - a adesão se deu em 2015 e ainda não há dados sobre que se valer em análise -, cuja resposta será dada segundo um olhar prospectivo, à luz do que se observa da experiência nacional e de acordo com o que se sabe do contexto regional e local onde se situa a instituição de ensino superior e das pessoas que buscam as oportunidades de se graduarem, não obstante as dificuldades por que passam no meio em que vivem.

A adesão da UERN ao Sisu foi realizada em 5 de dezembro de 2014, pela assinatura do Termo de Adesão (1ạ edição de 2015) da Sesu do MEC. Com essa adesão, a universidade manifestou seu desejo de utilizar a nota do Enem, por meio da plataforma do Sisu, para selecionar candidatos ao preenchimento de suas vagas de graduação. Essa nova sistemática de seleção já foi experimentada em 2015, mas ainda de forma parcial: conforme o Edital no 13/2014 (Comperve), 40\% das vagas iniciais para o ano letivo de 2015 foram preenchidas por intermédio do PSV e $60 \%$ por intermédio do Sisu. Contudo, nos anos posteriores, a expectativa é a de que seja utilizado o Sisu para selecionar candidatos à totalidade das vagas, mantendo-se a sistemática do sistema de cotas raciais e para portadores de deficiência, conforme imposição de lei estadual. A adesão integral da UERN ao Sisu representará o fim da utilização do PSV para o preenchimento das vagas de graduação da universidade.

Essa adesão constitui um passo importante em termos de promoção do acesso aos cursos de graduação da universidade, contribuindo para fomentar a democratização do acesso ao ensino superior no Meio-Oeste potiguar, assim como tem sido de uma forma geral, à semelhança da experiência nacional. Vale dizer, a princípio, que a maioria esmagadora das pessoas que têm pretensões às vagas de graduação da UERN - alunos de Mossoró, Assu, Patu, Caicó e cidades próximas, inclusive do Ceará - sequer têm condições de pagar o preço do PSV. O custo financeiro - não podemos negar - é uma das barreiras de acesso ao ensino superior a ser 
considerada. Com a adesão ao Sisu, o aluno somente terá que fazer o Enem, que é gratuito (para os de insuficiência financeira, como é o caso do público aqui considerado), sem inclusive ter que desembolsar os gastos com deslocamento para participar do PSV nos campi, uma vez que o Enem é realizado em cada cidade. Dessa forma, um estudante dos municípios cearenses de Russas, Limoeiro do Norte, Quixeré, por exemplo, de onde é grande o fluxo para a UERN, poderá fazer o Enem em sua cidade e concorrer a uma vaga na UERN sem precisar realizar qualquer gasto e deslocamento. É preciso ter sensibilidade para perceber que um recém-concludente do ensino médio, apesar de um bom aluno, não consegue chegar à universidade porque não encontra de onde tirar recursos para custear os gastos referentes à participação em um vestibular - é a realidade do Brasil, infelizmente!

No PSV, na fase de inscrição, previamente o candidato deve escolher o curso em que pretende graduar-se, caso passe na seleção, e concorrerá às vagas da opção que escolher, apenas. Em outras palavras, se optou pelo curso de Medicina, por exemplo, cuja nota de corte geralmente é a mais elevada, não assumirá uma vaga na UERN para cursar Medicina se não atingir o limite satisfatório de pontos no PSV para as vagas referentes a esse curso, tampouco assumirá qualquer outro curso da UERN, embora queira e tenha atingido pontuação suficiente para ser aprovado em qualquer outro curso ofertado. Se quiser ainda cursar Medicina ou outro curso na UERN, terá que se submeter a outro processo seletivo. Vaja-se o problema: nesse contexto, o sistema seletivo barra alunos mais preparados e seleciona alunos menos preparados! No exemplo citado, o discente que não conseguisse atingir uma pontuação satisfatória para a vaga em Medicina, também não assumiria uma vaga em qualquer outro curso, embora, com a sua pontuação, ficasse em primeiro ou nas primeiras colocações com relação a outros cursos. Com o Sisu, esse problema é corrigido, pois o candidato, com a nota do Enem, de sua casa, de um terminal de computador ligado à internet, poderá concorrer, de uma única vez, a até duas vagas e acompanhar seu desempenho durante o período de seleção, podendo alterar suas opções. Assim, o candidato, durante a etapa de inscrição, poderá acompanhar, pelo sistema do Sisu, o seu desempenho, trocando suas opções sempre que sua nota for insuficiente. Em outros termos, o candidato poderá testar sua nota para determinado curso, como Medicina, por exemplo, e se verificar, ao longo do processo seletivo, que sua nota será insuficiente, poderá cadastrá-la para outro curso de seu interesse quantas vezes forem necessárias durante a fase de seleção. 
Ademais, o Sisu oferece duas opções de inscrição - seleção em primeira opção e seleção em segunda opção -, ofertadas em períodos distintos, o que permite ao candidato não selecionado em primeira opção a chance de, em momento posterior, concorrer às vagas remanescentes, em igual sistemática descrita para a primeira opção. Apesar de tudo isso, ainda há formação de lista de espera para eventuais desistências de candidatos selecionados nas opções que antecederam. O Sisu, dessa forma, corrige o problema que o PSV apresentava: de deixar gente capacitada e preparada fora da universidade. O Sisu se mostra mais democrático nesse ponto, visto que, além de ser mais meritocrático, mostra-se mais razoável, eficiente, justo e afeto aos valores intrínsecos ao princípio democrático.

Enfim, a adesão da UERN ao Sisu constitui um passo importante em termos de promoção do acesso aos cursos de graduação da universidade, contribuindo para fomentar a democratização do acesso ao ensino superior, porque encurta distâncias (barreiras geográficas), diminui ou acaba com os gastos (barreiras financeiras) e permite a alocação da nota durante a fase de seleção, trazendo maior facilidade, comodidade, eficiência e meritocracia ao processo de seleção de candidatos às vagas ofertadas. Pelo Sisu, a probabilidade de o candidato conquistar uma vaga aumenta substancialmente, reduzindo o problema de ter que repetir o processo seletivo e a sensação de fracasso.

\section{CONSIDERAÇÕES FINAIS}

No Brasil, sempre vigorou um sistema elitista de acesso ao ensino superior, cuja justificativa tem raízes profundamente históricas. Esse sistema vai de encontro aos ditames do princípio democrático, que não se coaduna com essa profunda desigualdade educacional existente no país. Dessa forma, trabalhar tais questões - discuti-las em âmbito acadêmico - é uma forma de chamar a atenção de todos para a necessidade de se expandir, de se difundir o acesso ao ensino superior, contribuindo para mudar esse quadro educacional crônico, decorrente da própria construção histórica do país, marcada pelas desigualdades sociais e regionais. Para tanto, as políticas públicas educacionais devem ser implementadas com vista a atingir o maior número possível de indivíduos, assegurando condições reais, efetivas e equitativas de acesso, capazes de amenizar as dificuldades e desigualdades socioeconômicas, históricas e culturais existentes. 
Felizmente, mudanças estão ocorrendo, sobretudo nas últimas duas décadas. Graças a tais mudanças, o Brasil começa a avançar rumo a um sistema de massa no que toca ao acesso ao ensino superior, abandonando o velho modelo elitista, e isso se deve principalmente ao desenvolvimento de diversos programas educacionais e incentivos do Governo Federal. No tocante ao ensino superior, a oferta de vagas foi substancialmente ampliada e o acesso foi bastante facilitado, seja pela oferta de bolsas gratuitas totais e parciais e financiamento estudantil em universidades privadas, seja pela criação de diversas novas universidades públicas, do Sisu e do Enem. O Enem, em conjunto com outros programas do Governo Federal, como o Sisu, representa um enfrentamento contra os problemas de desigualdade educacional no Brasil, fomentando a democratização do acesso ao ensino superior.

O caráter democrático e plural do Enem/Sisu, como se demonstrou, impõe-se de suma importância como forma de enfrentar esse problema educacional brasileiro, ao possibilitar e facilitar o ingresso no ensino superior, de forma a contemplar todos os indivíduos, independentemente de sexo, cor, condição econômica, localização geográfica, etc. O Enem e o Sisu, nesse contexto, apresentam-se como mecanismos criados com a nítida finalidade de fazer com que a classe menos favorecida da sociedade possa ocupar os bancos das universidades públicas e privadas do país, de sorte a desvincular o acesso ao ensino superior da capacidade econômica e de questões geográficas e sociais.

No contexto da adesão da UERN ao Enem/Sisu, é perceptível a importância que isso representará para a democratização do acesso ao ensino superior no Oeste potiguar, assim como tem sido de uma forma geral, à semelhança da experiência nacional. A adesão constitui um passo importante em termos de promoção do acesso aos cursos de graduação da universidade, contribuindo para fomentar a democratização do acesso ao ensino superior, porque encurta distâncias (barreiras geográficas), diminui ou acaba com os gastos (barreiras financeiras) e permite a alocação da nota durante a fase de seleção, trazendo maior facilidade, comodidade, eficiência e meritocracia ao processo de seleção de candidatos às vagas ofertadas.

Educação \& Formação, Fortaleza, v. 2, n. 6, p. 165-185, set./dez. 2017

DOI: http://dx.doi.org/10.25053/edufor.v2i6.2580

http://seer.uece.br/redufor 


\section{REFERÊNCIAS}

BOBBIO, N. Estado, governo, sociedade: por uma teoria geral da política. Rio de Janeiro: Paz e Terra, 1987.

BONAVIDES, P. Ciência política. São Paulo: Malheiros, 1999.

BRASIL. Constituição de 1988. Constituição da República Federativa do Brasil. Diário Oficial [da] República Federativa do Brasil, Poder Executivo, Brasília, DF, 5 out. 1988.

BRASIL. Decreto no 5.296, de 2 de dezembro 2004. Regulamenta as Leis no 10.048 , de 8 de novembro de 2000, que dá prioridade de atendimento às pessoas que especifica, e $\mathrm{n} 010.098$, de 19 de dezembro de 2000, que estabelece normas gerais e critérios básicos para a promoção da acessibilidade das pessoas portadoras de deficiência ou com mobilidade reduzida, e da outras providências. Diário Oficial [da] República Federativa do Brasil, Poder Executivo, Brasília, DF, 3 dez. 2004.

BRASIL. Inep. Enem já é aceito por 87 instituições de ensino superior. 8 nov. 1999a. Disponível em: <http://portal.inep.gov.br/todas-noticias>. Acesso em: 22 fev. 2016.

BRASIL. Inep. Enem substituirá vestibular da Universidade do Grande ABC. 8 jun. 1999b. Disponível em: <http://portal.inep.gov.br/todas-noticias>. Acesso em: 22 fev. 2016.

BRASIL. Inep. Exame contou com a presença de 91\% dos inscritos. 14 dez. 1999c. Disponível em: <http://portal.inep.gov.br/todas-noticias>. Acesso em: 22 fev. 2016.

BRASIL. Inep. Número de inscritos no Enem 2003 é de quase 1,9 milhão. 21 ago. 2003. Disponível em: <http://portal.inep.gov.br/todas-noticias>. Acesso em: 22 fev. 2016.

BRASIL. Inep. O fim da obrigatoriedade do vestibular. 4 dez. 1998a. Disponível em: <http://portal.inep.gov.br/todas-noticias>. Acesso em: 22 fev. 2016.

BRASIL. Inep. Procura pelo Enem dobra em 2005. 30 dez. 2005. Disponível em: <http://portal.inep.gov.br/todas-noticias>. Acesso em: 22 fev. 2016.

BRASIL. Inep. Resultados do Enem serão aceitos por 93 instituições de ensino. 14 dez. 1999d. Disponível em: <http://portal.inep.gov.br/todas-noticias>. Acesso em: 22 fev. 2016.

BRASIL. Inep. Tudo pronto para aplicação do Enem 2010. 5 nov. 2010. Disponível em: <http://portal.inep.gov.br/todas-noticias>. Acesso em: 22 fev. 2016.

BRASIL. Inep. Universidades têm liberdade para definir uso do Enem. 18 jun. 1999e. Disponível em: <http://portal.inep.gov.br/todas-noticias>. Acesso em: 22 fev. 2016.

Educação \& Formação, Fortaleza, v. 2, n. 6, p. 165-185, set./dez. 2017

DOI: http://dx.doi.org/10.25053/edufor.v2i6.2580

http://seer.uece.br/redufor 
BRASIL. Lei no 9.394, de 20 de dezembro de 1996. Estabelece as Diretrizes e Bases da Educação Nacional. Diário Oficial [da] República Federativa do Brasil, Poder Executivo, Brasília, DF, 21 dez. 1996.

BRASIL. Portaria MEC no 438, de 28 de maio de 1998. Institui o Exame Nacional do Ensino Médio ENEM. Diário Oficial [da] República Federativa do Brasil, Poder Executivo, Brasília, DF, 29 maio $1998 \mathrm{~b}$.

BRASIL. Termo de adesão ao Sisu da UERN. Disponível em: <http://www.uern.br/controledepagi nas/informacoes-vestibular-comperve/arquivos/194237_1417806129117_termo_adesao_1987. pdf $>$. Acesso em: 10 abr. 2016.

DINIZ, M. H. Dicionário jurídico. São Paulo: Saraiva, 1998.

NERY JUNIOR, N. Princípios do processo civil à luz da Constituição Federal. São Paulo: Revista dos Tribunais, 1999.

RIO GRANDE DO NORTE. Lei no 8.258, de 27 de dezembro de 2002. Estabelece reserva de vagas nas Universidades Públicas Estaduais para alguns alunos egressos da Rede Pública de Ensino. Diário Oficial do Estado do Rio Grande do Norte, Poder Executivo, Natal, 28 dez. 2002.

RIO GRANDE DO NORTE. Lei no 9.696, de 25 de fevereiro de 2013. Dispõe sobre a reserva de 5\% das vagas para pessoas Portadoras de Necessidades Especiais nos cursos de graduação oferecidos pela Universidade Estadual do Rio Grande do Norte - UERN em todas as suas unidades de ensino e dá outras providências. Diário Oficial do Estado do Rio Grande do Norte, Poder Executivo, Natal, 26 fev. 2013.

NUNES, P. Dicionário de tecnologia jurídica. Rio de Janeiro: Freitas Bastos, 1993.

RISTOFF, D. O novo perfil do campus brasileiro: uma análise do perfil socioeconômico do estudante de graduação. Avaliação, Campinas, v. 19, n. 3, p. 723-747, 2014.

SANTOS, J. M. C. T.; SILVA, M. K.; MELO, S. F. Adesão da UERN ao Enem e a democratização do acesso ao ensino superior. Holos, Natal, v. 3, n. 33, p. 16-31, 2017.

UERN. Edital no 13/2014 - Comperve. PSVI/2014, no ano letivo de 2015. Disponível em: <http:// www.uern.br/controledepaginas/comperve-editais-vestibular/arquivos/1876edital_na_ 13.2014 _psvi_2015_abertura_do_psv_ok.pdf>. Acesso em: 10 abr. 2016.

UERN. Edital no 15/2013 - Comperve. PSV/2014, no ano letivo de 2014. Disponível em: <http://www.uern.br/controledepaginas/compervenoticias/arquivos/1887edital_na_15.2013_ps v_2014_abertura_do_psv.pdf>. Acesso em: 10 abr. 2016.

Recebido em 5 de junho de 2017.

Aceito em 10 de novembro de 2017.

Educação \& Formação, Fortaleza, v. 2, n. 6, p. 165-185, set./dez. 2017

DOI: http://dx.doi.org/10.25053/edufor.v2i6.2580

http://seer.uece.br/redufor 